\title{
Migration of sulphur in thermal barrier coatings during heat treatment
}

\author{
Mingwen Bai ${ }^{\text {a }}$, Haibo Jiang ${ }^{\mathrm{b}}$, Ying Chen ${ }^{\mathrm{a}}$, Yiqiang Chen ${ }^{\mathrm{c}}$, Chris Grovenor ${ }^{\mathrm{d}}$, Xiaofeng Zhao ${ }^{\mathrm{e}}$, Ping Xiao ${ }^{\mathrm{a}, *}$ \\ a School of Materials, University of Manchester, Manchester, UK \\ b Centre for Microscopy, Characterisation and Analysis, The University of Western Australia, Perth, Australia \\ c Monash Centre for Electron Microscopy, Monash University, Victoria 3800, Australia \\ ${ }^{d}$ Materials Department, Oxford University, Oxford, UK \\ e Shanghai Key Laboratory of Advanced High-temperature and Precision Forming, Shanghai Jiao Tong University, Shanghai, China
}

\section{A R T I C L E I N F O}

\section{Article history:}

Received 22 November 2015

Received in revised form 15 February 2016

Accepted 25 February 2016

Available online 27 February 2016

\section{Keywords:}

Thermal barrier coatings (TBCs)

Sulphur

Oxidation

Adhesion

Second ion mass spectrometry (SIMS)

Transmission electron microscopy (TEM)

\begin{abstract}
A B S T R A C T
The sulphur effect in thermal barrier coatings (TBCs) mainly refers to a segregation of sulphur at the interface between thermally grown oxide (TGO) and the bond coat, which significantly deteriorates scale adhesion to alloys. Restricted by the extremely low concentrations of sulphur $(0-10 \mathrm{ppm})$ in TBCs, previous investigations using conventional analytical techniques failed to provide a complete mechanism for the migration of sulphur. In this study, high resolution secondary ion mass spectrometry (NanoSIMS) was employed to detect trace sulphur distributions in commercial TBCs. After heat treatments, sulphur segregates at three typical areas in TBCs: (1) the yttria stabilized zirconia (YSZ) top coat; (2) the TGO/bond coat interface and (3) the grit blasted surface. This indicates that during heat treatment a significant outward diffusion of sulphur occurs from the superalloy to YSZ top coat through the TGO, and a possible mechanism for the migration of sulphur in TBCs is described. The undesired "sulphur effect" on scale adhesion was suggested to be caused by the formation of residual sulphides beneath the alumina scale with weaker ionic bonding to alloy cations. Possible solutions are suggested aiming to alleviate the sulphur effect in TBCs.
\end{abstract}

(c) 2016 Elsevier Ltd. All rights reserved.

\section{Introduction}

The degradation of thermal barrier coatings (TBCs) mainly depends on the stability of the protective oxide scale produced by oxidation of the bond coat alloys [1]. The adhesion at the clean TGO/bond coat interface (e.g. $\mathrm{Al}_{2} \mathrm{O}_{3} / \mathrm{Ni}$ interface) is fundamentally strong, because it involves both covalent and ionic bonds [2]. However, it is significantly compromised by the presence of trace impurities (e.g. sulphur, carbon, etc.), which results in a greater tendency for scale spallation. Among these, sulphur is the most detrimental impurity, and has been widely studied for decades on both $\mathrm{Al}_{2} \mathrm{O}_{3}$ and $\mathrm{Cr}_{2} \mathrm{O}_{3}$ scale formers [3-6]. Although the normal bulk sulphur level in superalloys is only tens of parts per million (10 ppm), a significant improvement in scale retention can be achieved if the superalloys are desulfurized to an ultra-low level $(<1 \mathrm{ppm})[7,8]$. The segregation of sulphur at the TGO/bond coat interface at very low levels was suggested to decrease scale adhesion by up to $70 \%[9-11]$.

Nevertheless, the complete mechanism for the migration of sulphur during oxidation is still a subject of debate; while at the same time approaches are urgently needed to alleviate the deleterious effect of sulphur on scale adhesion. Earlier studies suggested that during oxidation

\footnotetext{
* Corresponding author.

E-mail address: p.xiao@manchester.ac.uk (P.Xiao).
}

sulphur migrates from the inner alloy to the TGO/bond coat interface and weakens the interface in the same way as it embrittles alloy grain boundaries [3]. Grabke et al. [12] suggested that sulphur tends to absorb on free alloy surfaces within the voids at the TGO/bond coat interface, which promotes the growths of voids and defects, and therefore decreases the critical stress required for spallation. Recent developments of advanced analytical instruments have provided more accurate observations. Auger electron spectroscopy (AES) has revealed that sulphur does indeed segregate at the TGO/bond coat interfaces [13]. It was also suggested using analytical transmission electron microscopy (TEM) that the segregation of sulphur occurs not only in voids or cavities but also in regions of contact [14]. Gheno et al. [15,16] used secondary ion mass spectrometry (SIMS) depth profiling to observe the distribution of sulphur in Ni-based superalloys, as well as TBCs, and observed sulphur hotspots in low resolution images. We are, however, still uncertain about the form of segregated sulphur, i.e. either as sulphur ions or sulphur atoms. In this study, sulphur distributions with a greater area scope in commercial TBCs was analysed by using a Cameca NanoSIMS, which is an SIMS instrument specifically designed for high spatial resolution (down to $50 \mathrm{~nm}$ ) imaging while still maintaining high mass resolution and high sensitivity. Subsequently, energy dispersive X-ray spectroscopy (EDX) under higher spatial resolution scanning transmission electron microscopy (STEM) was employed to examine the sulphur segregation in localized areas identified in the NanoSIMS. 


\section{Experiments}

\subsection{Sample preparations}

TBC samples were taken from high-pressure turbine blades provided by Rolls Royce plc, which consist of a 7-8 wt\% YSZ top coat deposited by electron beam physical vapour deposition (EBPVD), a Pt-aluminide $\beta$-phase bond coat (32Pt 18.9Al 35.1Ni 5.1Co 2.2Cr 1.7 W 0.3Ta in wt.\%) and a CMSX-4 single crystal superalloy (Ni 9.6Co 6.4Cr $6.4 \mathrm{~W}$ 6.6Ta 5.6Al 2.9Re 1.03Ti 0.1Hf in wt.\%). As-received TBC samples were sectioned from turbine blades with an average width of $12 \mathrm{~mm}$, pre-treated at $1150{ }^{\circ} \mathrm{C}$ for $1 \mathrm{~h}$ in laboratory air, and then subjected to an isothermal treatment at $1150{ }^{\circ} \mathrm{C}$ for $100 \mathrm{~h}$ in laboratory air and in vacuum $\left(1 \times 10^{-5}-1 \times 10^{-6} \mathrm{mBar}\right)$, which is later referred to as long-term oxidation and diffusion treatments respectively. After the required exposure time, TBC samples were rapidly cooled to room temperature by using an automatic lifting platform $\left(\mathrm{CM}^{\mathrm{TM}}\right)$ and a powerful cooling fan. Both heating and cooling were completed in $<10 \mathrm{~min}$.

\subsection{Characterization methods}

Cross-sectional microstructures of the TBCs samples were examined by using a scanning electron microscope (SEM, FEI Quanta 650). Observation of trace sulphur distributions in TBCs was performed by high-resolution SIMS analysis using a CAMECA NanoSIMS50 (CAMECA, France) operating with a $16 \mathrm{keV}$ primary $\mathrm{Cs}^{+}$beam. Quantitative mappings of Pt and S were drawn according to the counts per second (cps). Line scans and area mappings were carried out by STEM imaging combined with EDX analysis (Oxford Instruments X-MaxN 80 T SDD) on a TEM (FEI Tecnai F30) operating at $300 \mathrm{keV}$. The S/TEM samples were prepared by focused ion beam (FIB, FEI Quanta 3D) using the in-situ lift-out technique.

\subsection{Thermodynamic calculations}

The Gibbs energy of chemical reactions is calculated at $1150{ }^{\circ} \mathrm{C}$ by using the Thermo-Calc software (Version 4.1) with the TCS Ni-based Superalloys Database (TCNI6) and the SGTE Substances Database (SSUB5). The calculations are based on thermodynamic parameters, which are produced through critical assessment and systematic evaluation of experimental and theoretical data, following the wellestablished CALPHAD technique [17].

\section{Results and discussion}

\subsection{Sulphur in TBCS}

Fig. 1 shows NanoSIMS images of Pt and S distributions on the crosssections of TBCs after different heat treatments: (A) as-received; (B) after treatment at $1150{ }^{\circ} \mathrm{C}$ in vacuum for $100 \mathrm{~h}$; and (C) after treatment at $1150{ }^{\circ} \mathrm{C}$ in air for $100 \mathrm{~h}$. The colour scale on the right side indicates the counts of $32 \mathrm{~S}(0-15 \mathrm{cps})$ and $195 \mathrm{Pt}$ ( $0-40 \mathrm{cps})$. After oxidation, a significant increase of total $\mathrm{S}$ counts is observed in comparison with the as-received sample. According to the NanoSIMS maps, S mainly segregates in three typical areas: (1) YSZ top coat; (2) TGO/bond coat interface; and (3) grit blasted surface (i.e. the original superalloy surface prior to deposition of the Pt layer $\sim 10 \mu \mathrm{m}$ from the TGO/bond coat interface). These three typical areas for $\mathrm{S}$ segregation all involve ceramic oxides, i.e. the YSZ top coat, the $\mathrm{Al}_{2} \mathrm{O}_{3}$ scale and the embedded $\mathrm{Al}_{2} \mathrm{O}_{3}$ grits (marked by white arrows). On the other hand, the $\mathrm{S}$ shows no preferential segregation in the alloys matrix, i.e. no difference in $S$ content is observed between the $\beta$-phase and $\gamma^{\prime}$-phase (which forms due to the depletion of Al during oxidation), or between high and low-Pt regions identified in the NanoSIMS Pt maps. These NanoSIMS results indicate that $S$ interacts more strongly with the ceramic oxides rather than

\section{BSE}

SE

$\mathrm{Pt}$
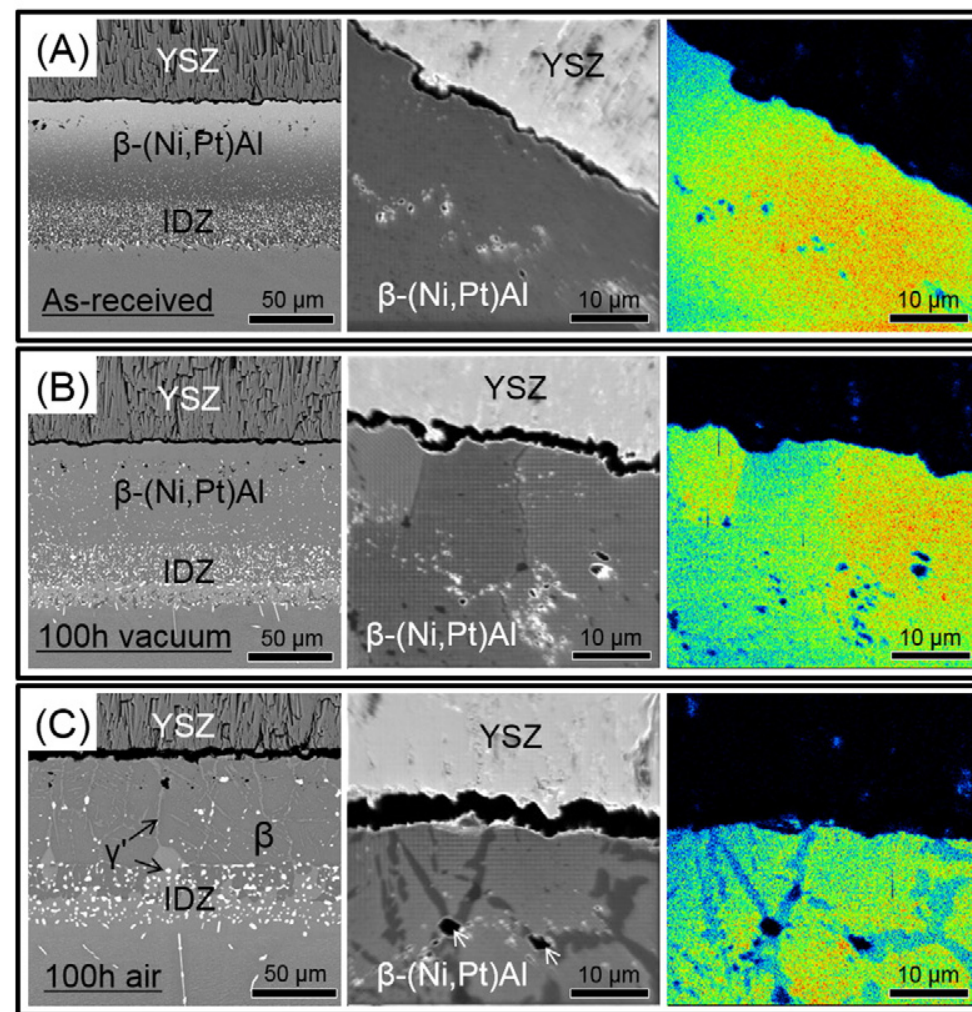

$S$
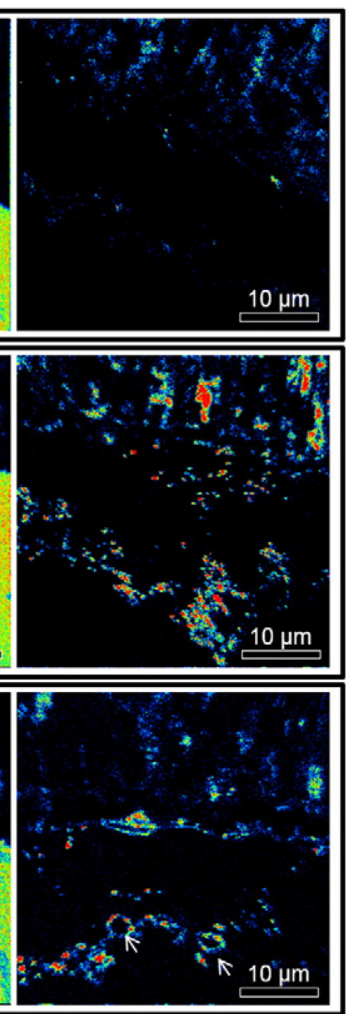

Unit

(cps) Max.
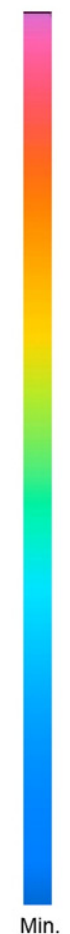

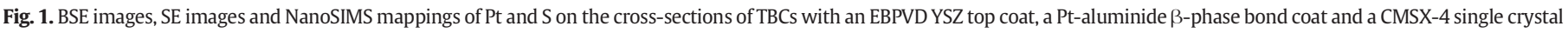

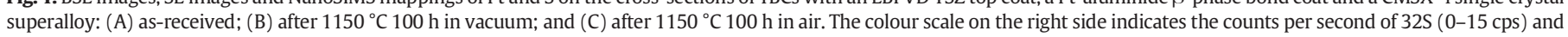
195Pt (0-40 cps). 
alloys, and that Pt is not as effective in capturing $\mathrm{S}$ as is proposed in the literature [18]. Further investigations on the segregation of $S$ at these three typical areas, all of which involve ceramic oxides, were carried out using STEM/EDS.

\subsection{Sulphur in the YSZ top coat}

NanoSIMS images showed that the distribution of S in the YSZ top coat after oxidation follows a columnar morphology similar to the microstructure of the EBPVD YSZ top coat shown in Fig. 1. In addition, after diffusion in vacuum, more $S$ is observed in the YSZ top coat, while the segregation of $S$ is less obvious at the TGO/bond coat interface. In the YSZ top coat, $\mathrm{S}$ is detected either in the columnar bulk oxides or inter-columnar gaps (closed pores). Fig. 2 shows a STEM image focusing on the YSZ top coat near the TGO/top coat interface in the cross-section of a TBCs annealed at $1150^{\circ} \mathrm{C}$ for $100 \mathrm{~h}$ in vacuum. EDS line scan profiles (see the typical examples in Line scan 1 and 2 in Fig. 2) indicate an increase of $S$ content from the TGO to the YSZ top coat, with S concentrated in the YSZ columnar bulks rather than the inter-columnar gaps. $S$ can reside as $\mathrm{S}^{2-}$ ions in the ionic crystal of YSZ by substituting for $\mathrm{O}^{2-}$ ions and result in the formation of ZrOS (zirconium oxy-sulphide) or $\mathrm{ZrS}_{2}$ (zirconium sulphide), both of which are commonly found in YSZ solid electrolyte [19-21]. $\mathrm{S}^{2-}$ ions (184 pm) have the same valence state and similar ionic radius to $\mathrm{O}^{2-}$ ions (140 pm). YSZ solid solutions also show high oxygen vacancy mobility at high temperatures due to the dopant of $\mathrm{Y}_{2} \mathrm{O}_{3}$. Rapid migration of $\mathrm{S}^{2-}$ ion in the YSZ top coat will be promoted by these vacancy sites, which we would expect to result in a columnar-shape distribution of $\mathrm{S}$. On the other hand, $\mathrm{Y}_{2} \mathrm{O}_{3}$ doping in the $\mathrm{ZrO}_{2}$ lattice could also contribute to capturing $\mathrm{S}$, as it is known that the addition of reactive elements (RE) or their oxides can significantly improve the scale adhesion on Ni-alloys [22,23]. Our observation of S in the YSZ top coat confirms that outward diffusion of $S$ from the superalloys to the YSZ top coat can occur through the alumina scale.

\subsection{Sulphur at the TGO/bond coat interface}

Considering the dense microstructure of the alumina scale, it is unlikely that $\mathrm{S}$ is able to diffuse through the alumina scale in an atomic form and must form $\mathrm{S}^{2-}$ ions. Therefore, the formation of $\mathrm{S}^{2-}$ ions must have taken place beneath the alumina scale, and then the $S^{2-}$ ions can diffuse outwards through the alumina grain boundaries as $\mathrm{O}^{2-}$ and $\mathrm{Al}^{3+}$ ions do during high temperature oxidation. There are two possible mechanisms for the ionization process of $\mathrm{S}$ atoms beneath the alumina scale. The first could be achieved by exchanging electrons with $\mathrm{O}^{2-}$ ions according to reaction (1), which is quite similar to the mechanism of desulphurization in the electro slag re-melting (ESR) process to remove S from Ni- and Fe-based alloys [24]. The second possible mechanism could be the exchange of electrons with $\mathrm{Al}$ atoms according to reaction (2). Both reactions are feasible

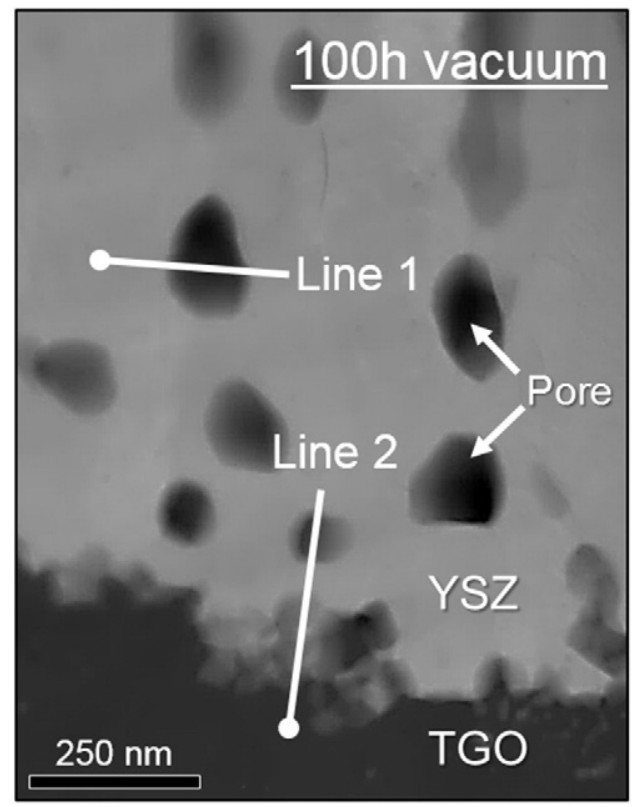

\section{EDX line scan: Line 1}

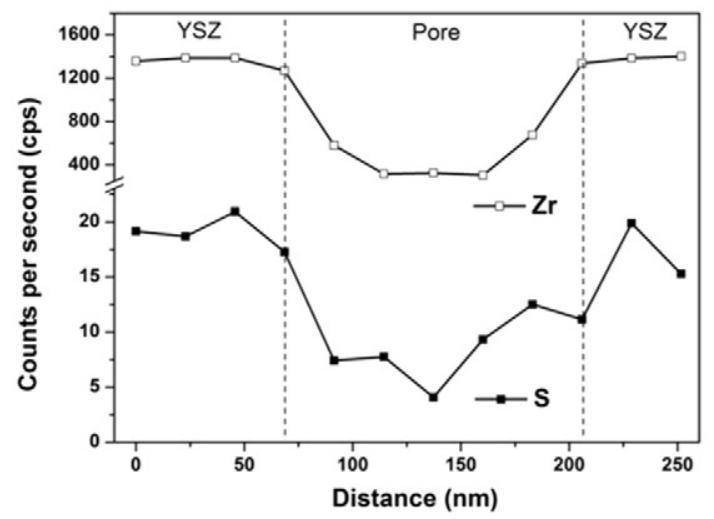

\section{EDX line scan: Line 2}
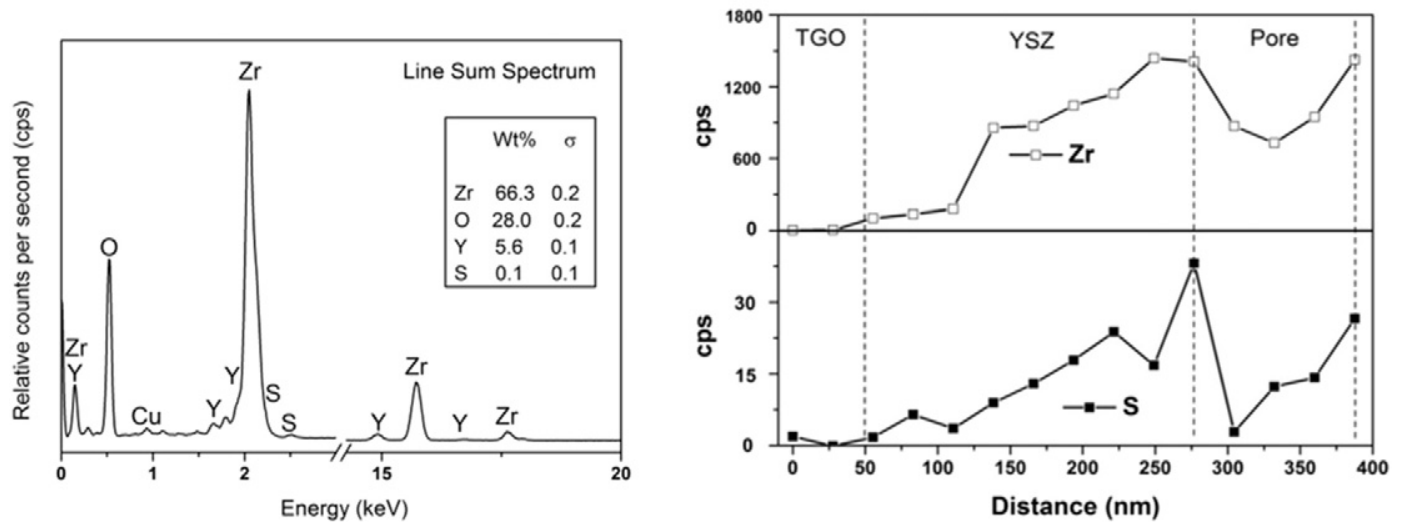

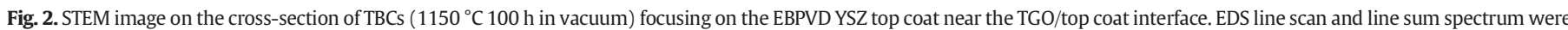
acquired from Line 1 and Line 2. 
thermodynamically, and result in the formation of $\mathrm{Al}_{2} \mathrm{~S}_{3}$, which is a sulphide with a weak ionic-covalent S-Al bonds $\left(0.36 \mathrm{~J} / \mathrm{m}^{2}\right)$ [9].

$$
\begin{aligned}
& 2 \mathrm{O}^{2-}+2 \mathrm{~S} \rightarrow 2 \mathrm{~S}^{2-}+\mathrm{O}_{2}, \Delta \mathrm{G}=-9.09 \times 10^{4} \mathrm{~J} / \mathrm{mol}, 1150{ }^{\circ} \mathrm{C}(\mathrm{CaO}) \\
& 2 \mathrm{Al}+3 \mathrm{~S} \rightarrow 3 \mathrm{~S}^{2-}+2 \mathrm{Al}^{3+}, \quad \Delta \mathrm{G}=-8.45 \times 10^{5} \mathrm{~J} / \mathrm{mol}, 1150{ }^{\circ} \mathrm{C}
\end{aligned}
$$

Once the ionization of $\mathrm{S}$ is complete, the outwards diffusion of $\mathrm{S}^{2-}$ ions and the inwards diffusion of $\mathrm{O}^{2-}$ ions will both be through grain boundaries in the alumina scale, but in opposite directions. These possible diffusion paths are clearly revealed in the BSE and STEM images in Fig. 3, which show the morphology of the alumina grains after different heat treatments [25]. During oxidation, it is possible that the grain boundaries diffusion is mainly dominated by the inwards diffusion of $\mathrm{O}^{2-}$ ions, which will block the diffusion path and inhibit the outwards diffusion of $S^{2-}$ ions. In addition, the thickening and the elongation of the alumina grains due to ongoing oxidation will create additional oxide that prevents the migration of $\mathrm{S}^{2-}$ ions through the alumina layer. As a result, more $S^{2-}$ ions remain beneath the alumina scale and segregate at the TGO/bond coat interface. On the other hand, during treatment in vacuum, the oxygen partial pressure is extremely low $\left(2.1-21 \times 10^{-10} \mathrm{~atm}\right)$ so the rate of inward diffusion of $\mathrm{O}^{2-}$ ions is less than that under oxidation, and more $\mathrm{S}^{2-}$ ions are able to diffuse outwards towards YSZ top coat. Although the thickening and elongation of the alumina columnar grains is also observed in the sample treated in vacuum, the growth rate is quite slow and the grain boundary density (i.e. effective diffusion paths) remains relatively high as the equiaxed grain structure is preserved in the outer layer. These favourable conditions in vacuum would therefore encourage more outwards diffusion of $\mathrm{S}^{2-}$ ions through the thin alumina layer, and result in a higher content of $\mathrm{S}$ in the YSZ top coat and less segregation of S at the TGO/bond coat interface.
The segregation of $\mathrm{S}$ at the TGO/bond coat interface has been further investigated on these TBC samples after oxidation by using EDS/STEM. EDS maps were acquired on a typical void area at the TGO/bond coat interface (Fig. 4). S does not preferentially segregate at these interfacial voids. The free alloy surface at the interfacial void area is in fact covered by $\mathrm{Cr}$ and $\mathrm{Re}$. The coverage of these elements on the free alloy surface would impede the diffusion of $\mathrm{Al}$ to form new oxide that could fill the voids. The interfacial voids are therefore preserved, and may even grow and coalesce during heat treatments, which could play a more important role in determining the interfacial adhesion in comparison with the $\mathrm{S}$ segregation effect.

\subsection{Sulphur at the grit blasted surface area}

Another site shown by the NanoSIMS data to have strong segregation of $\mathrm{S}$ is at the grit blasted surface area, which has been rarely studied before mainly due to the fact that the residual grit oxides are usually quite small and far away from the TGO layer $(10 \sim 15 \mu \mathrm{m})$. The NanoSIMS analysis in this study has revealed that the internal oxides have absorbed a significant amount of $\mathrm{S}$. This could be beneficial for TBC lifetime by alleviating the $S$ segregation at the TGO/bond coat interface. Therefore, the segregation of $\mathrm{S}$ around the internal grits is worth investigating. The industrial standard grit blasting process usually employs fine $\mathrm{Al}_{2} \mathrm{O}_{3}$ particles, with common impurities such as $\mathrm{TiO}_{2}, \mathrm{SiO}_{2}$, $\mathrm{CaO}, \mathrm{MgO}$ etc. $(<0.1 \mathrm{wt} \%$ of each) $[26,27]$. The size and the distribution of residual $\mathrm{Al}_{2} \mathrm{O}_{3}$ grits in the TBCs are quite random, and one typical area containing large $\mathrm{Al}_{2} \mathrm{O}_{3}$ grit oxides was extracted for further study (Fig. 5).

The interface between the $\mathrm{Al}_{2} \mathrm{O}_{3}$ grit and bond coat alloy is shown in Fig. 6. The EDS maps reveal that not only $S$ segregates at the interface but also $\mathrm{Cr}$ which partially surrounds the $\mathrm{Al}_{2} \mathrm{O}_{3}$ grit. EDS line scans were undertaken at both interfaces with and without $\mathrm{Cr}$ that Line 1 shows a high peak of $\mathrm{S}$ at the position where both $\mathrm{Al}$ and $\mathrm{O}$ start to
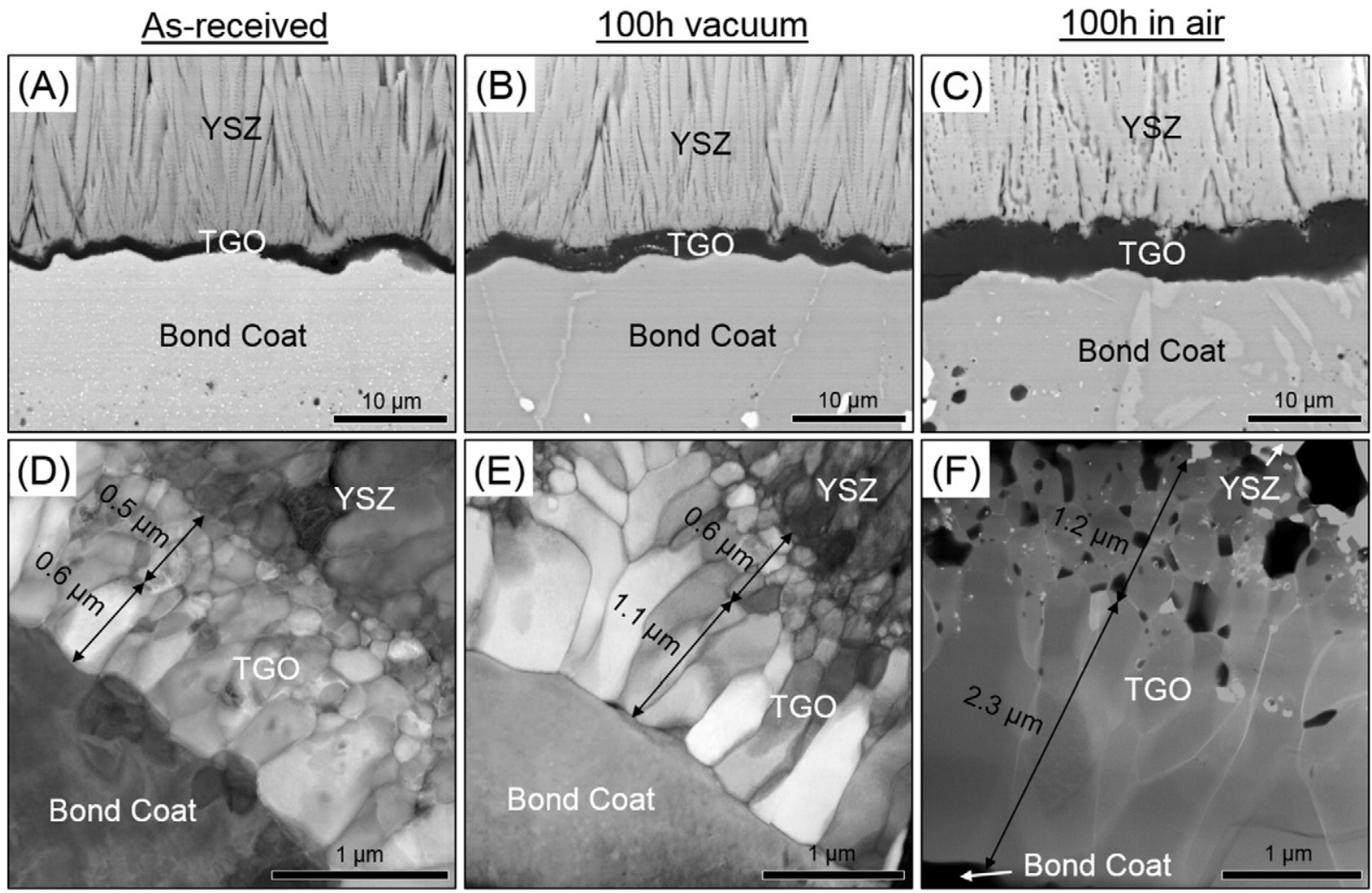

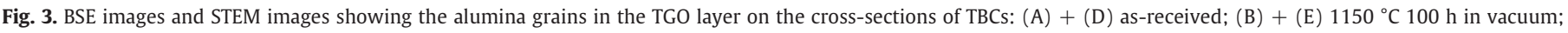

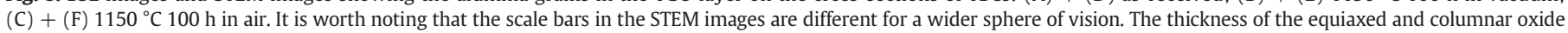
layer is also measured and marked on the STEM images. 


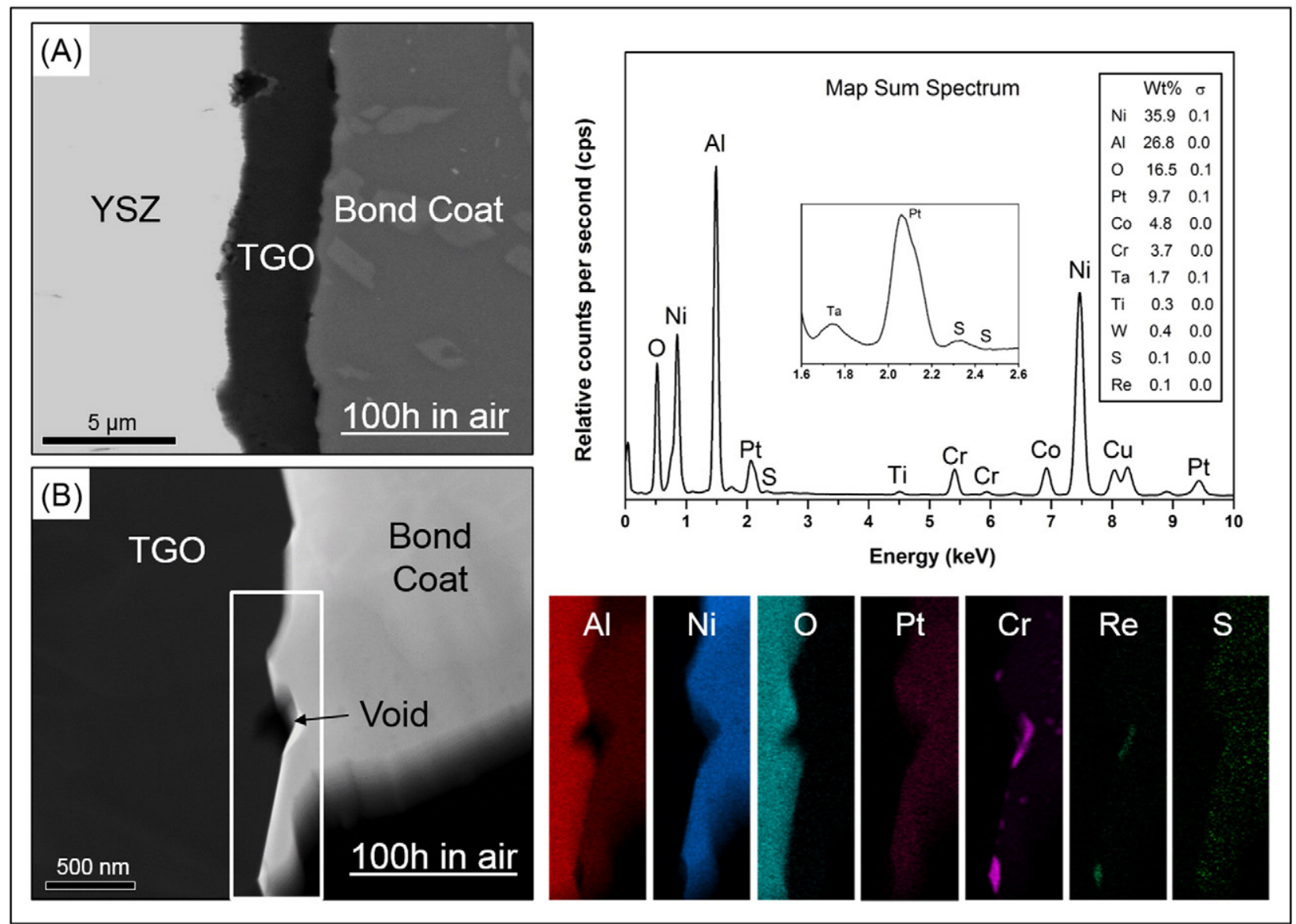

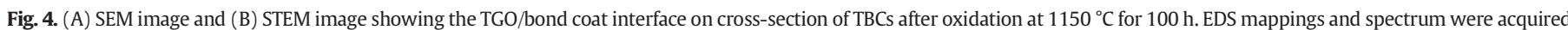
from the white rectangular area focusing on an interfacial void.
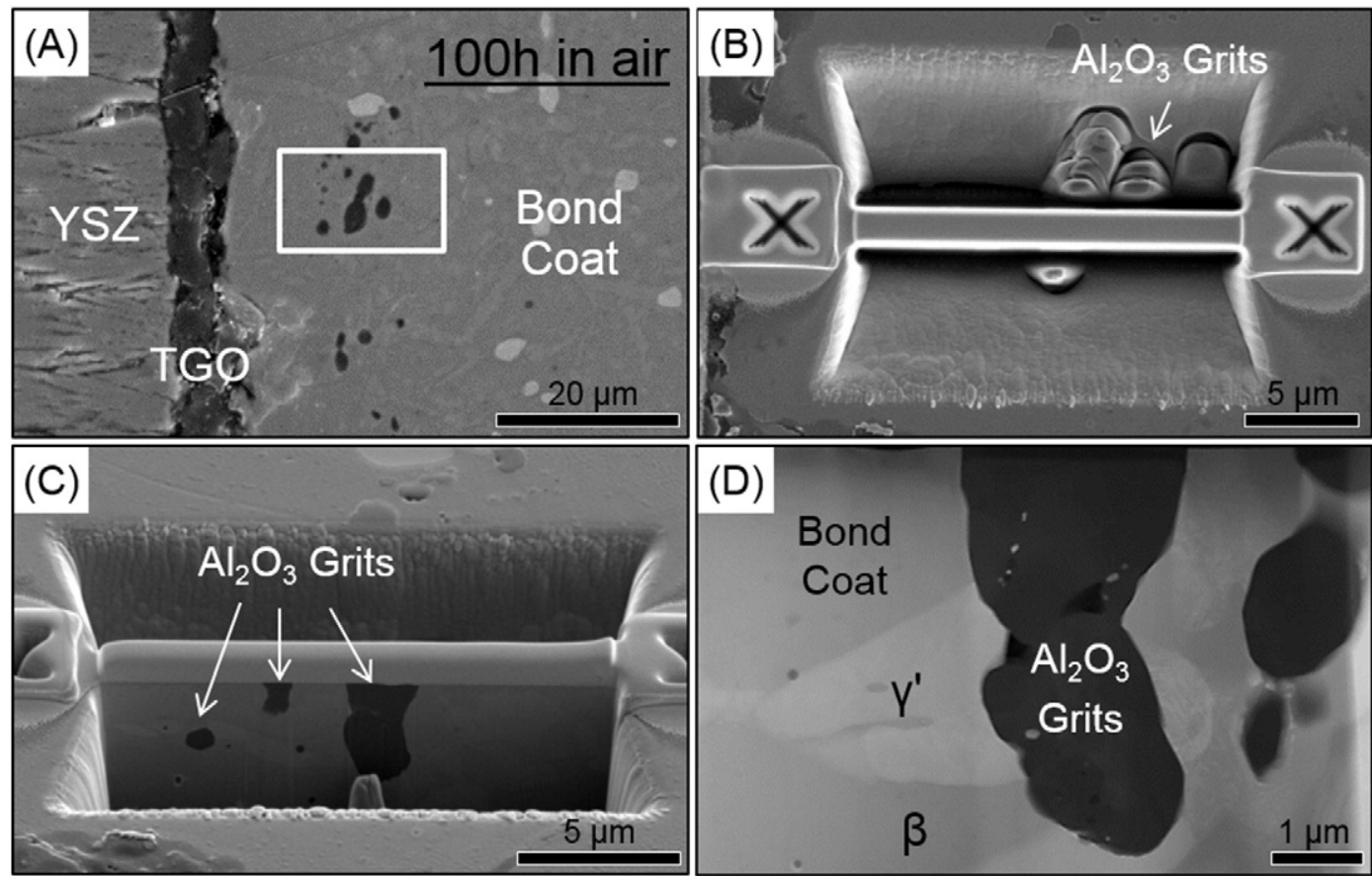

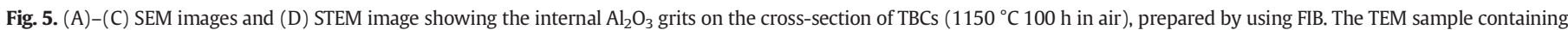
large $\mathrm{Al}_{2} \mathrm{O}_{3}$ grits was extracted from the rectangular area. 

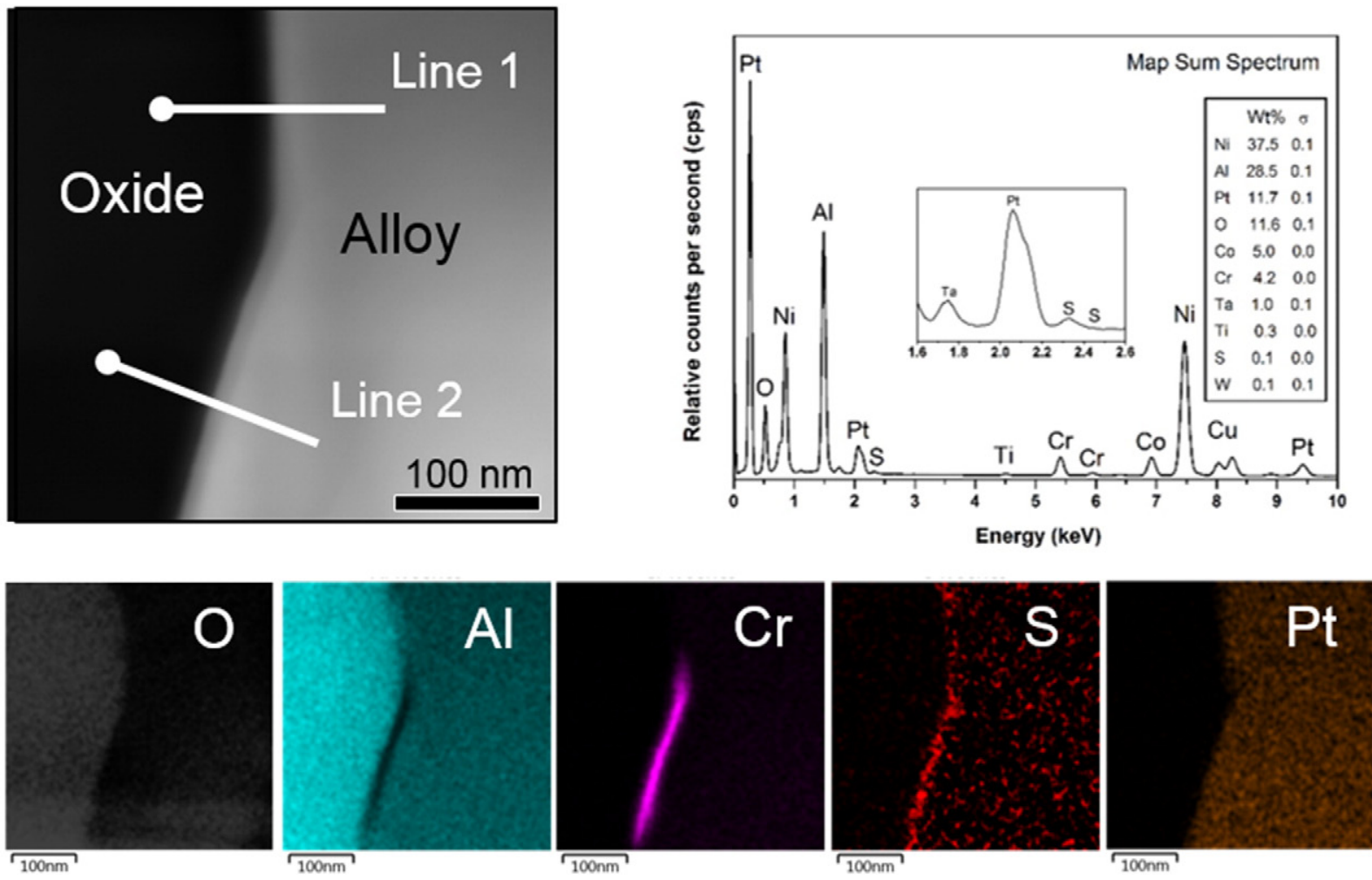

\section{EDS line scan: Line 1}
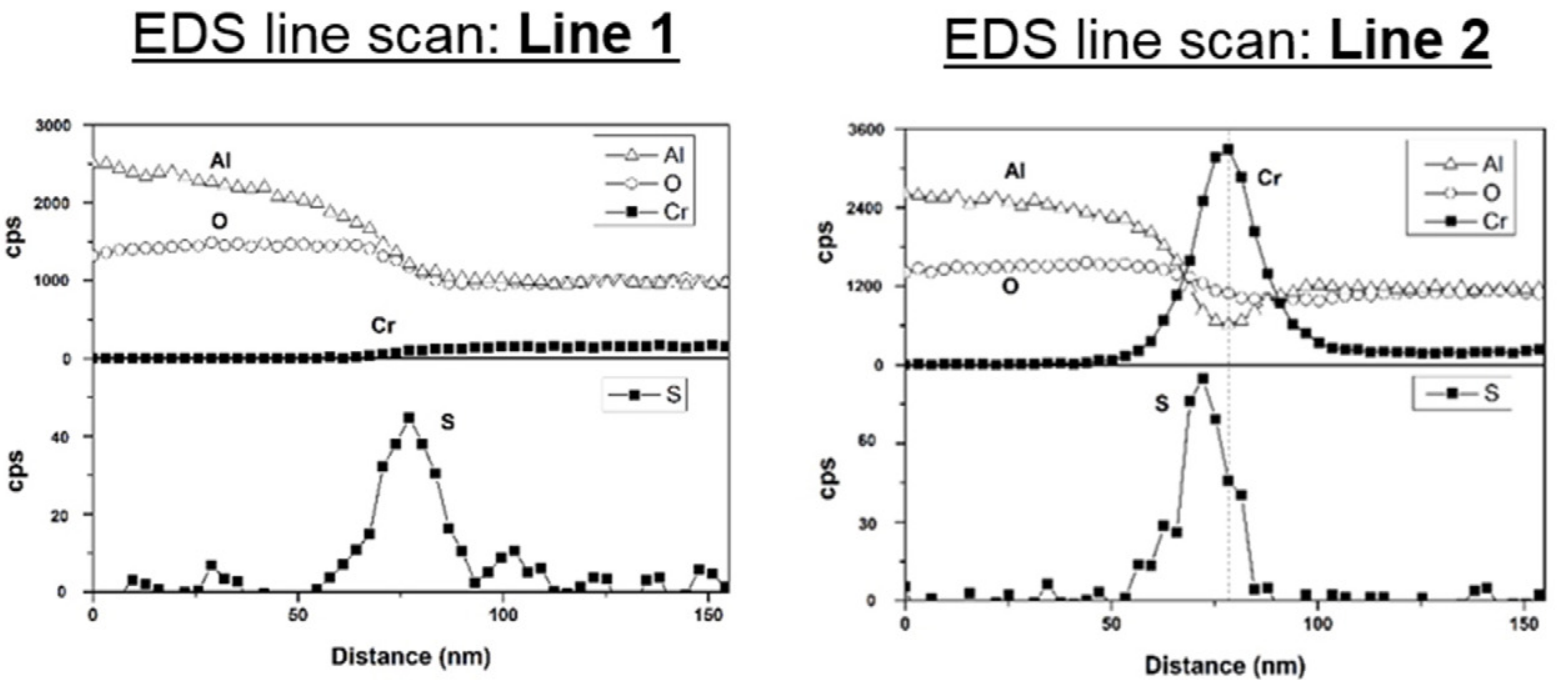

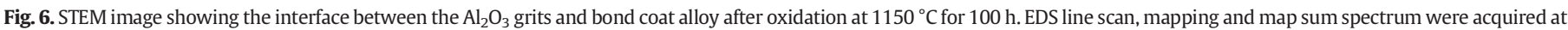
the oxide/alloy interface.

increase and Line 2 shows a peak of $\mathrm{Cr}$ at a position where a low concentration of $\mathrm{Al}$ is also observed. If the interface between oxide and bond coat alloy is free of ionic-covalent bonds (in physical contact), Grabke et al. [28] suggested that the segregation of $S$ at the grit blasted surface area is more likely to be driven by the large tendency for $\mathrm{S}$ atoms to segregate at the free alloy surface.

However, more experimental evidence is required to support this interpretation. Firstly, it might not be true that the interface between the internal oxides and bond coat alloys is just in physical contact and completely free of ionic-covalent bonds. Growth of internal oxide particles after long-term heat treatments can be indicated by large particles in the cross-sectional SEM images in Fig. 1, and was also observed in other studies $[29,30]$. This indicates that internal oxidation can occur at the grit oxide/alloy interface, in a similar manner as oxidation occurs at the TGO/alloy interface. The oxide particles and the bond coat alloys would thus be ionic-covalent bonded, and we would expect $S$ to segregate as stable sulphides such as $\mathrm{Al}_{2} \mathrm{~S}_{3}$ or $\mathrm{Cr}_{2} \mathrm{~S}_{3}$ at the grit/alloy interface. This agrees with the previous discussion that $\mathrm{S}^{2-}$ ions segregate at the TGO/bond coat interface as sulphide, mainly due to the great similarities between these two oxide/alloy interfaces, both containing ionic-covalent bonds.

\subsection{Migration of Sulphur in TBCS}

It is worth noting that the raw YSZ top coat materials in this study were prepared according to industrial standards, which therefore contain very low levels of impurities (e.g. S). In addition, we do not believe that it is likely that we are introducing $S$ from the laboratory environment, especially under vacuum condition. We conclude that $\mathrm{S}$ mainly originates from the superalloy substrates, which usually contain 
0-10 ppm of S (depending on whether a desulphurisation process is applied) [31]. At high temperatures, $S$ tends to diffuse outwards from the bulk metal to the alloy surface, driven by the high saturated vapour pressure of S (approximately of $316 \mathrm{~atm}$ at $1150^{\circ} \mathrm{C}$, according to the formula reported by Rau et al. [32]). This driving force for the outwards diffusion of $\mathrm{S}$ would be promoted under vacuum conditions $\left(10^{-8}-10^{-9} \mathrm{~atm}\right.$ in this study). In addition, the YSZ top coat acts like both a natural reservoir and an effective conductor for $S^{2-}$ ions to form a stable sulphide in YSZ solid solutions. The constant consumption of $\mathrm{S}^{2-}$ ions could influence the thermodynamic driving force for the migration of $\mathrm{S}$ through grain boundaries in the TGO layer, and promote more outwards diffusion of S in TBCs. The well-known tendency for $\mathrm{S}$ to segregate at Ni-alloy free surfaces and alloy/scale interfaces is driven by a decrease in surface or interface energy by saturation of free bonds, and a decrease in elastic energy by release of stresses in the lattice caused by dissolved atoms $[12,15]$. However, the segregation of atomic $\mathrm{S}$ at the TGO/bond coat interface should not occur for two reasons: (1) there are no free metal bonds as the metal cations and scale oxygen anions are firmly tied into ionic bonds; and (2) there is no such free space for the larger size of $\mathrm{S}$ atoms between the bond coat alloy surface and the alumina scale. As a result, the most likely form for the segregation of $\mathrm{S}$ at the intact TGO/bond coat interface is as a sulphide. For the unattached areas at the TGO/bond coat interface, such as voids or imperfections, the surface of the bond coat alloy becomes a possible location for saturated S atoms [33]. However, the STEM/EDS results indicate that alloying precipitates (e.g. $\mathrm{Cr}$ ) rather than $\mathrm{S}$ segregate at the surface of the interfacial voids and contribute most to retain the interfacial voids by inhibiting the growth of alumina scale. More importantly, it also showed that $\mathrm{S}$ does not have a preferential segregation place at either the intact area or the interfacial voids. In other words, the free alloy surface at the interfacial voids does not necessarily offer a preferred location for the segregation of S.
Fig. 7 shows schematic illustrations of the key mechanisms we propose for the migration of $S$ in TBCs during oxidation, based on the above investigations on the three typical areas to which we have observed that $\mathrm{S}$ segregates. Internal $\mathrm{Al}_{2} \mathrm{O}_{3}$ grit particles absorbed a significant amount of $\mathrm{S}$ from the bulk alloy, which can alleviate the detrimental effect caused by the segregation of $\mathrm{S}$ at the TGO/bond coat interface. S would segregate at the grit oxide/alloy interface as $\mathrm{Al}_{2} \mathrm{~S}_{3}$ sulphide in a similar way as the segregation at the TGO/bond coat interface. Ionization of $\mathrm{S}$ occurs underneath the alumina scale and on the grit oxide surface, and the $S^{2-}$ ions then diffuse outwards towards the YSZ top coat through the alumina grain boundaries in a competition with the opposite diffusion of $\mathrm{O}^{2-}$ ions. The vacuum annealing treatment would accelerate this migration of $S^{2-}$ ions by inhibiting both the inwards diffusion of $\mathrm{O}^{2-}$ ions and the growth of alumina grains. The outwards diffusion of $\mathrm{S}^{2-}$ ions is then consumed in the YSZ top coat by substituting for $\mathrm{O}^{2-}$ ions, which enables the formation of $\mathrm{ZrO}(2-\mathrm{x}) \mathrm{S}_{\mathrm{x}} \cdot \mathrm{Y}_{2} \mathrm{O}_{3}$ solid solutions. The thickening of the alumina scale and consequent elongation of the alumina grains during oxidation in air would also create a kinetic barrier for the outwards diffusion of $\mathrm{S}^{2-}$ ions, so that residual sulphide remains preferentially at the TGO/bond coat interface.

Although a number of studies have demonstrated the presence of sulphur at $\mathrm{Al}_{2} \mathrm{O}_{3}$ /bond coat layer interfaces, the detailed mechanism of the origin of the loss of adhesion remains under discussion [1]. Indirect methods have been applied to indicate the loss of TBCs adhesion caused by the segregation of sulphur. Hou et al. [34] used a scratching method on the oxidized samples in ultra-high vacuum. The scratch plows through the scale into the metal, causing oxide spallation adjacent to the scratch mark. It could indicate strong interface adhesion if the oxide scale was difficult to scratch off. More importantly, Auger analyses on exposed area indicated that the segregation of sulphur beneath the oxide lead to spallation of the scale. Therefore, based on the literatures on the sulphur study, it was assumed in this study that sulphur in

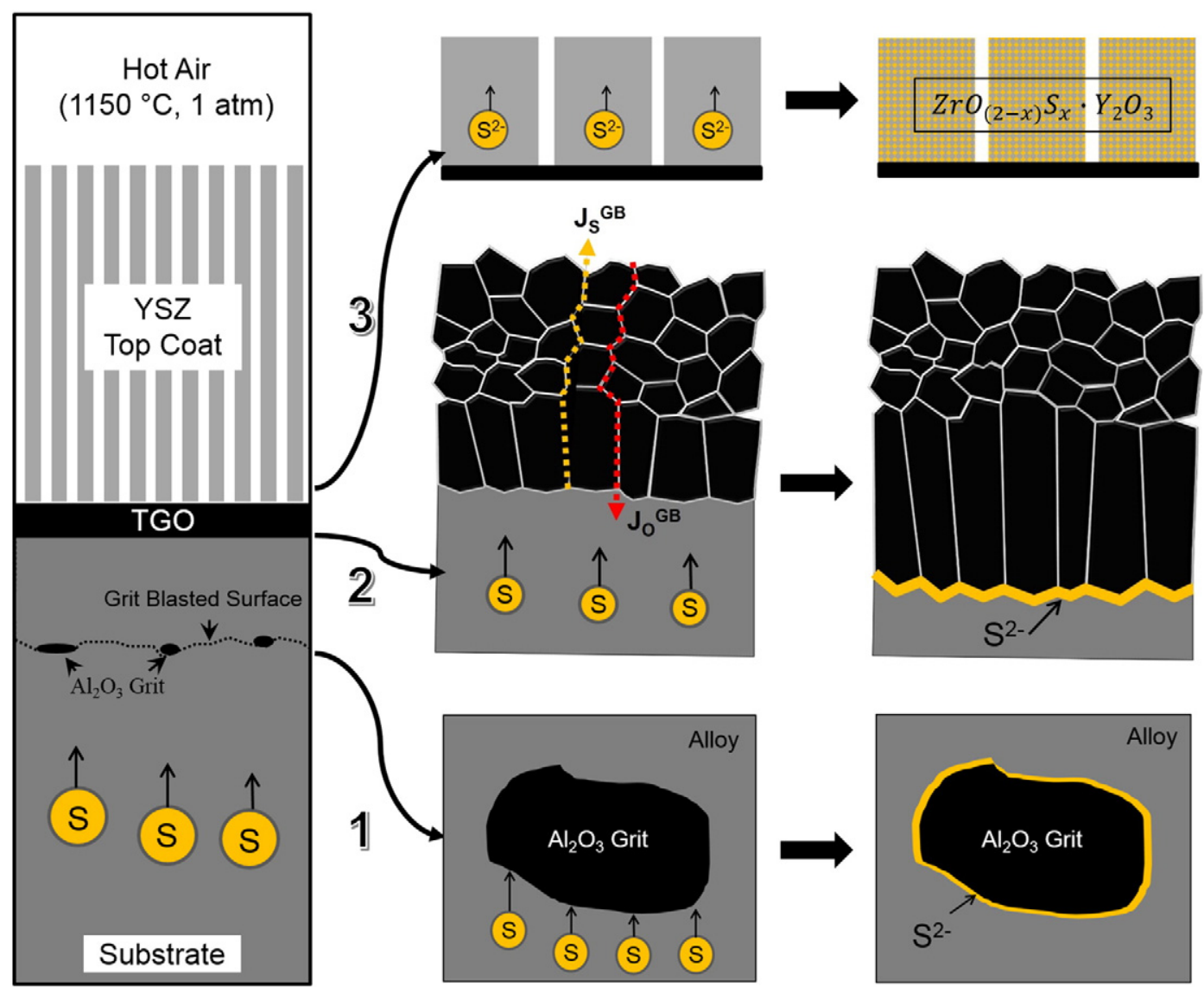

Fig. 7. Schematic illustrations of the migration of sulphur in TBCs during oxidation. 
TBCs is a key factor, although other factors would also contribute to the failure of TBCs, such as rumpling/ratcheting, void formation, and other extrinsic factors [9].

It is also worth mentioning that the internal grit oxides have indeed absorbed a significant amount of $\mathrm{S}$, which could alleviate the detrimental effect on scale adhesion caused by the segregation of $\mathrm{S}$ at the TGO/ bond coat interface. Therefore, improvement could be made by employing new oxide grits during the grit blasting process of Ni-based superalloys prior to the electroplating of Pt. A wider selection of ceramic oxides could be explored, including RE oxides such as $\mathrm{ZrO}_{2}$ and $\mathrm{Y}_{2} \mathrm{O}_{3}$, etc. The addition of RE oxides could prove effective since it is well known that pure RE elements can sequester $\mathrm{S}$, and have been added for many years to oxide dispersion strengthened (ODS) alloys [35-37]. We speculate that these new oxide grits could act more efficiently in absorbing sulphur than the conventional grits that mainly contain $\mathrm{Al}_{2} \mathrm{O}_{3}$, and could possibly improve TGO adhesion and TBC durability to the extent that less Pt would be required for the bond coat so that production costs could be reduced.

\section{Conclusions}

In this study, the segregation of $\mathrm{S}$ in TBCs was investigated by using Nano SIMS mapping and STEM/EDS analysis. After oxidation at $1150^{\circ} \mathrm{C}$ for $100 \mathrm{~h}$, segregations of $\mathrm{S}$ was observed at three typical areas in TBCs: (1) the YSZ top coat; (2) the TGO/bond coat interface and (3) the grit blasted surface area. These were further investigated by using higher resolution STEM/EDX analysis. Internal alumina grits and the YSZ top coat have absorbed a significant amount of $S$, which could alleviate the detrimental effect caused by the segregation of $\mathrm{S}$ at the TGO/bond coat interface. It was also found that alloying precipitates $(\mathrm{Cr}$ and $\mathrm{Re})$ segregated at the interfacial voids contributed more to retaining the interfacial voids by inhibiting the growth of alumina scale than $\mathrm{S}$. The undesired "sulphur effect" on scale adhesion was suggested to be caused by the formation of residual sulphides beneath the scale with weaker ionic bonding strength to alloy cations rather than a segregation of sulphur atoms.

\section{Acknowledgment}

The author would like to thank Mr. Andy Wallwork, Dr. Ali Gholinia and Mr. Matthew Smith for the experimental assistance. The authors would also like to acknowledge Dr. David Rickerby from Rolls-Royce for the supply of TBCs sample.

\section{References}

[1] I. Rouzou, R. Molins, L. Rémy, F. Jomard, Study of the sulfur segregation for a TBC System, Mater. Sci. Forum Trans. Tech. Publ. (2004) 101-108.

[2] K.A. Marino, B. Hinnemann, E.A. Carter, Atomic-scale insight and design principles for turbine engine thermal barrier coatings from theory, Proc. Natl. Acad. Sci. 108 (2011) 5480-5487.

[3] Y. Ikeda, M. Tosa, K. Yoshihara, K. Nii, Adherence of $\mathrm{Al}_{2} \mathrm{O} 3$ coating layers to steels: the detrimental effect of sulphur and the beneficial effect of rare earth metals, Mater. Sci. Eng. A 120 (1989) 179-184.

[4] D.W. Parker, Thermal barrier coatings for gas turbines, automotive engines and diesel equipment, Mater. Des. 13 (1992) 345-351.

[5] L. Geng, Y.-S. Na, N.-K. Park, Oxidation behavior of alloy 718 at a high temperature, Mater. Des. 28 (2007) 978-981.
[6] D.W. Yun, S. Seo, H. Jeong, Y. Yoo, The cyclic oxidation behaviour of Ni-based superalloy GTD-111 with sulphur impurities at $1100{ }^{\circ}$ C, Corros. Sci. 90 (2015) 392-401.

[7] N. Bornstein, M. DeCrescente, J. Smeggil, The influence of sulfur on the oxidation of coatings, Mater. Sci. Eng. A 120 (1989) 175-178.

[8] J.L. Smialek, B.A. Pint, Optimizing scale adhesion on single crystal superalloys, Mater. Sci. Forum Trans. Tech. Publ. (2001) 459-466.

[9] A.G. Evans, D.R. Clarke, C.G. Levi, The influence of oxides on the performance of advanced gas turbines, J. Eur. Ceram. Soc. 28 (2008) 1405-1419.

[10] B. Hinnemann, E.A. Carter, Adsorption of Al, O, Hf, Y, Pt, and S atoms on $\alpha-\mathrm{Al} 2 \mathrm{O} 3$ (0001), J. Phys. Chem. C 111 (2007) 7105-7126.

[11] W. Zhang, J. Smith, A. Evans, The connection between ab initio calculations and interface adhesion measurements on metal/oxide systems: Ni/Al2O3 and $\mathrm{Cu} / \mathrm{Al} 2 \mathrm{O} 3$, Acta Mater. 50 (2002) 3803-3816.

[12] H. Grabke, G. Kurbatov, H. Schmutzler, Segregation beneath oxide scales, Oxid. Met. 43 (1995) 97-114.

[13] P. Hou, J. Moskito, Sulfur segregation to Al2O3-FeAl interfaces studied by Field emission-auger electron spectroscopy, Oxid. Met. 59 (2003) 559-574.

[14] P. Fox, D. Lees, G. Lorimer, Sulfur segregation during the high-temperature oxidation of chromium, Oxid. Met. 36 (1991) 491.

[15] T. Gheno, D. Monceau, D. Oquab, Y. Cadoret, Characterization of sulfur distribution in Ni-based superalloy and thermal barrier coatings after high temperature oxidation: A SIMS analysis, Oxid. Met. 73 (2010) 95-113.

[16] M. Chieux, C. Duhamel, R. Molins, F. Jomard, L. Rémy, J.-Y. Guédou, Sulfur localization in NiPtAl/superalloy systems after high temperature isothermal oxidation, Oxid. Met. 81 (2014) 115-125.

[17] J.O. Andersson, T. Helander, L. Höglund, P. Shi, B. Sundman, Thermo-calc \& DICTRA, computational tools for materials science, Calphad 26 (2002) 273-312.

[18] X. Zhao, P. Xiao, Effect of platinum on the durability of thermal barrier systems with a gamma plus gamma ' bond coat, Thin Solid Films 517 (2008) 828-834

[19] Z.-T. Sui, X.-Y. Xiao, K.-Q. Huang, C.-Z. Wang, Standard Gibbs free energy of formation of ZrOS, J. Less Common Met. 163 (1990) 109-113.

[20] Q.M. Nguyen, Solid oxide fuel cell technology-features and applications, Solid State Ionics 174 (2004) 271-277.

[21] Z. Lv, R. Guo, P. Yao, F. Dai, Effects of $\mathrm{Al} 2 \mathrm{O} 3$ and/or CaO on properties of yttria stabilized zirconia electrolyte doped with multi-elements, Mater. Des. 28 (2007) 1399-1403.

[22] B. Kazimierzak, J.M. Prignon, R.I. Fromont, An ODS material with outstanding creep and oxidation resistance above $1100{ }^{\circ} \mathrm{C}$, Mater. Des. 13 (1992) 67-70.

[23] D. Li, H. Guo, D. Wang, T. Zhang, S. Gong, H. Xu, Cyclic oxidation of $\beta-N i A l$ with various reactive element dopants at $1200{ }^{\circ} \mathrm{C}$, Corros. Sci. 66 (2013) 125-135.

[24] J.M. Hampshire, The role of materials in the design and application of rolling contact bearings, Mater. Des. 7 (1986) 192-197.

[25] M. Bai, E. Sarakinou, Y. Chen, A.D. Chandio, X. Zhao, M. Preuss, et al, Microtexture analysis of the alumina scale in thermal barrier coatings, J. Am. Ceram. Soc. 98 (2015) 3639-3642.

[26] V. Tolpygo, D. Clarke, K. Murphy, The effect of grit blasting on the oxidation behavior of a platinum-modified nickel-aluminide coating, Metall. Mater. Trans. A 32 (2001) 1467-1478.

[27] K.P. Chander, M. Vashista, K. Sabiruddin, S. Paul, P. Bandyopadhyay, Effects of grit blasting on surface properties of steel substrates, Mater. Des. 30 (2009) 2895-2902.

[28] H.J. Grabke, Surface and interface segregation in the oxidation of metals, Surf. Interface Anal. 30 (2000) 112-119.

[29] J.A. Haynes, B.A. Pint, Y. Zhang, I.G. Wright, The effect of Pt content on $\gamma-\gamma^{\prime}$ NiPtAl coatings, Surf. Coat. Technol. 203 (2008) 413-416.

[30] R.T. Wu, R.C. Reed, On the compatibility of single crystal superalloys with a thermal barrier coating system, Acta Mater. 56 (2008) 313-323.

[31] M. Pomeroy, Coatings for gas turbine materials and long term stability issues, Mater. Des. 26 (2005) 223-231.

[32] H. Rau, T.R.N. Kutty, J.R.F. Guedes de Carvalho, High temperature saturated vapour pressure of sulphur and the estimation of its critical quantities, J. Chem. Thermodyn. 5 (1973) 291-302

[33] H.J. Grabke, D. Wiemer, H. Viefhaus, Segregation of sulfur during growth of oxide scales, Appl. Surf. Sci. 47 (1991) 243-250.

[34] P.Y. Hou, V.K. Tolpygo, Examination of the platinum effect on the oxidation behavior of nickel-aluminide coatings, Surf. Coat. Technol. 202 (2007) 623-627.

[35] B.A. Pint, J. Leibowitz, J.H. DeVan, Effect of an oxide dispersion on the critical Al content in Fe-Al alloys, Oxid. Met. 51 (1999) 181-197.

[36] P.Y. Hou, J. Stringer, Effect of surface-applied reactive element oxide on the oxidation of binary alloys containing Cr, J. Electrochem. Soc. 134 (1987) 1836-1849.

[37] Z. Shi, F. Han, The microstructure and mechanical properties of micro-scale Y2O3 strengthened $9 \mathrm{Cr}$ steel fabricated by vacuum casting, Mater. Des. 66 (2015) 304-308. 